\title{
Educational Modules on Solar Energy
}

\section{Dr. Jason M. Keith, Mississippi State University}

Jason M. Keith is Professor and Director of the Dave C. Swalm School of Chemical Engineering at Mississippi State University. He also holds the Earnest W. Deavenport, Jr. Chair. Jason has been active in ASEE since 2001. In 2011, he received the Joseph J. Martin Award from ASEE-CHED with his coauthors for the best paper in the chemical engineering division at the 2010 meeting. He also has received the Raymond W. Fahien Award from ASEE-CHED in 2008. Jason currently teaches the graduate level advanced process computations and the undergraduate level process control course.

\section{Liz Rayfield, Dave C. Swalm School of Chemical Engineering Mississippi State University}

Liz Rayfield is a Junior majoring in Chemical Engineering at Dave C. Swalm School of Chemical Engineering, Mississippi State University. She is also working toward The Environment \& Sustainability Certificate at Mississippi State University. She has previously been a coauthor of the publication "Role of the Rostrum in Swimming Performance of Juvenile Paddlefish (Polyodon spathula)," published in the American Fisheries Society on the research she did on the swimming capabilities of paddlefish. She is currently a co-op student with The Dow Chemical Company. In the Spring of 2014 she will be conducting bio-fuels research with Dr. French at Mississippi State University after attending the Global Renewable Energy Education Network study abroad in Costa Rica in January 2014. Her research interests include renewable and sustainable energy sources. Her intended undergraduate graduation date is December 2015.

\section{Niraj Kashinath Palsule, Mississippi State University}

Niraj Palsule is a Junior majoring in Chemical Engineering at Dave C. Swalm School of Chemical Engineering, Mississippi State University. He originally hails from India and completed his high school education there itself. He holds a Energy Innovation and Emerging Technologies Certificate from Stanford Center for Professional Development, Stanford University. His research interests are educational research, market analysis and manufacturing of photovoltaics. 


\section{Abstract}

This paper describes the development of educational modules which provide a multi-disciplinary knowledge of solar energy and which can be incorporated in the curriculum of chemical engineering, mechanical engineering and electrical engineering, among others. Through these modules, we have made an effort to provide basic information to students on the economic, technical, and policy based aspects of solar energy. Apart from this, we are working on a module on tools which help to simulate the output and finances of solar energy installation. Every module contains background information, worked example problems and homework problems. Thus, these modules also act as a compendium of in-class and/or homework problems. Journal articles, online databases from government websites like NREL and EPA, and books are used as references while preparing these modules. Every module is published online at the energy module website http://tinyurl.com/hailstatesolar and is easily and openly accessible to any interested individual for downloading. They can be used as a teaching aid in any related course. Such usage would help to increase student awareness of and interest in solar energy. This research takes inspiration from a successful similar project on Hydrogen Fuel Cell Technology.

\section{Objectives and Motivation}

The need for utilizing clean energy is widely accepted throughout the world and is no longer a topic of debate or discussion. In his 2011 State of Union Address, President Obama called for a goal of achieving $80 \%$ of America's electricity through clean energy sources by $2035^{1}$. Among all the alternative energy sources, solar energy has played and will play a pivotal role in meeting this goal. The support of the Obama administration for solar energy can be symbolically understood by the installation of solar panels at the White House. The support for solar energy is seen across the political spectrum. According to a survey by Solar Energy Industries Association in 2011, 80\% of Republicans, $90 \%$ of Independents and 94\% of Democrats agree that it is imperative for the U.S. to develop and use solar energy ${ }^{2}$. Solar Energy is a highly growing and a highly researched field. The total installed capacity in United States doubled in just one year from May 2012 to May 2013³. U.S Department of Energy allocated \$310M to the SunShot Initiative in FY2013. This amount is more than what was allocated for any other alternative energy resource (Biomass - \$270M, Wind - \$95M, Geothermal - \$65M) ${ }^{4}$. Due to these efforts, about 120,000 new jobs have been created $^{5}$.

In order to maintain this growth and meet the future demands of this industry, a skilled workforce is necessary. The only way to create a skilled workforce is through proper training and education. Generally, courses in the engineering curriculum across universities in United States lack inclusion of concepts related to solar energy in their coursework. The modules that we have prepared can be used as teaching aid to include the fundamental concepts of solar energy in the engineering curriculum. They can be utilized parallel to the coursework in the courses related to the modules. Another advantage of these modules is that they act as a compendium of problems 
related to solar energy. This paper describes the structure of these modules and provides sample modules for better understanding.

There are existing web-based compendiums of modules online. Bio-related modules have been developed for the material and energy balance course at the bioengineering educational materials bank $^{6}$ : (http://www.bioemb.net). There are also materials related online modules exist at the materials digital library pathway ${ }^{7}$ : (http://matdl.org), and there is a large amount of content for all engineering courses and topics which can be found at the Massachusetts Institute of Technology open courseware site (http://ocw.mit.edu) and the Multimedia Educational Resource for Learning and Online Teaching site ${ }^{9}$ (http://www.merlot.org). There is also a compendium of hydrogen energy ${ }^{10}$ (http://www.che.msstate.edu/pdfs/h2ed/) and alternative energy ${ }^{11}$ (http://www.che.msstate.edu/pdfs/energy/index.html) modules online.

\section{Multidisciplinary Nature of Solar Energy}

Consider a photovoltaic installation on an individual's roof-top. Apart from the higher efficiency of the panels, the individual will also look for a cheaper material for panels. In order to regain a part of his investment, he might think of selling the excess electricity produced. Thus like any other method for power generation, utilization of Solar Energy is not solely based on science or engineering. Factors like finances and policy making also play an important role in its development. This multidisciplinary nature of Solar Energy is illustrated in Figure 1. As a result, it would not be sufficient to provide students with only the technical knowledge of Solar Energy. Keeping this aim in mind, we have tried to cover the non-technical topics of solar energy as well through our modules.

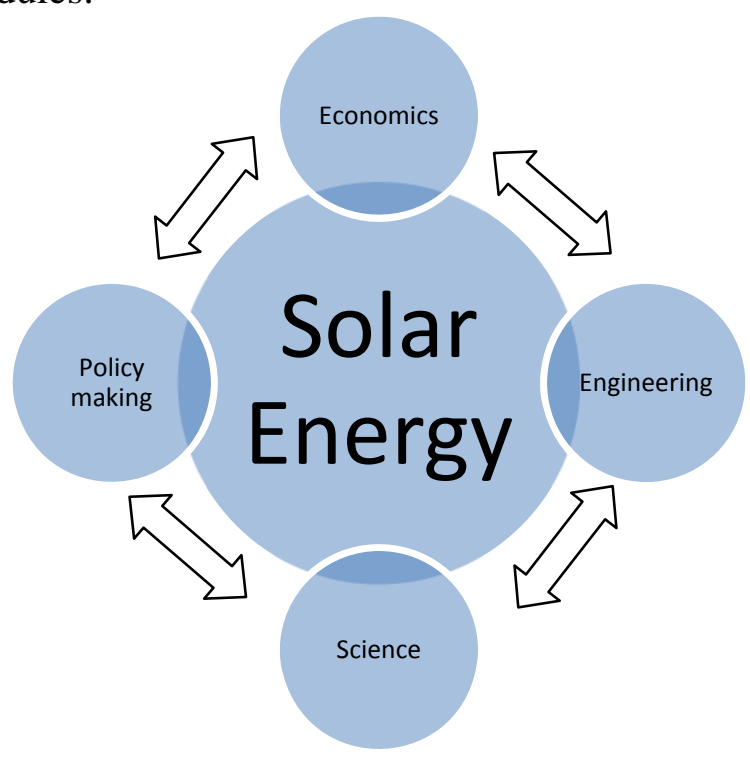

Figure 1. Cross-Integration of Technical and Non-Technical Concepts in Solar Energy

Solar Energy Module Development

Every module is structured with an aim to make it user-friendly for both instructors and students. Each module contains topic introduction, necessary background data, references with links, 2-3 
example problems and their solutions and 2-3 homework problems and their solutions. The topic introduction gives a brief description about the concepts presented in the module. The references used in the modules are books, journal articles and online databases. Students are generally not aware of the wide range of information openly available through databases on websites of government agencies like U.S. Department of Energy (DOE), Environmental Protection Agency (EPA) and National Renewable Energy Lab (NREL). These modules would help to increase this awareness as well. The solutions to the example problems and homework problems are provided in a step-by-step approach so that students can understand the procedure without any external help. Example problems and homework problems range from being simple to complex.

Apart from the conceptual modules prepared so far, we have also prepared two modules on the use of simulation tools available on the internet. One is on the PVWatts module and the other is on the System Advisor Model (SAM), both made available for use for free by NREL. Each of these modules provides the steps that are used to simulate an installation and determine its output with the help of an example. Students also learn about the various parameters involved in photovoltaic installations as well. These tools are often used to get a quick estimation of the energy output of a solar array.

Following is the list of modules that have been prepared so far:

- The Power of Solar Energy

- Solar Water Heating

- Solar Steam Turbine

- Solar Fill Factor

- Solar Panel Economics

- Policies Related to Residential Solar Energy Usage

- Absorber Material Usage

- Energy Payback Time

- Greenhouse Gas Emissions

- Power and Inverters

- Using the PV Watts Tool

- Using the SAM Software Tool

Utilization of Modules as a Teaching Aid

All the topics of modules which we have earlier mentioned are related to courses in the engineering curriculum in chemical, mechanical, and electrical engineering as well as in materials science and engineering. Using them as a part of the course work would increase the awareness and spread the knowledge about fundamental concepts of solar energy. Instructors as well as students can easily download these modules on http://tinyurl.com/hailstatesolar. It is rarely seen that examples related to alternative energy or solar energy in particular are provided by instructors while teaching a course. These modules can be used to provide such real-life 
examples through a problem-solving approach. This might increase the curiosity of students towards solar energy. For example, the module titled Absorber Material Usage contains fundamentals related to mass balance. If this module is used a teaching aid by an instructor teaching mass balance, it would generate awareness about solar energy as well.

Also, exposure to various databases used as references in the modules would probably increase the critical thinking of students. The information that students would gain would be beneficial for them while preparing reports, presentations and projects during their entire engineering study. To give an example, the module titled Greenhouse Gas Emissions contains the Emissions \& Generation Resource Integrated Database (eGRID) database as a reference. This database is generated by EPA and is contains data related to the output, corresponding emissions and resource mix of power plants across the United States.

Future Directions

Our module development is in the initial stages and we plan to achieve the following objectives in the future:

- Module assessment will be carried out by testing them in both required and elective courses both in chemical engineering and in other engineering disciplines. Student surveys will be developed through Institutional Review Board to determine their effectiveness.

- Develop more modules so as to cover a range of topics sufficient enough to provide a multidisciplinary knowledge of solar energy.

- Develop module assessment tools to evaluate the modules from the perspective of both instructors and students, so that necessary improvements can be made.

- Additional dissemination through various conferences to increase the awareness about these modules within the professional community

New module ideas are most welcomed and instructors are encouraged for their participation in module development and utilization.

Conclusion

In this paper we have described the development of educational modules on solar energy and its importance for inclusion in the engineering curriculum. The significance of these modules as a teaching aid for instructors is also explained. Each module has a topic introduction, references with links, background data, example problem statement, example problem solution, homework problem statement and homework problem solution. We hope to increase the awareness of solar energy among students through these modules.

Acknowledgements 
The authors would like to acknowledge financial support from the Earnest W. Deavenport, Jr. Chair in the Dave C. Swalm School of Chemical Engineering at Mississippi State University. The CACHE Corporation is also acknowledged for posting the module locations and their help in dissemination of these modules.

Bibliography

1. 2011 State of the Union Address, available online at: http://www. whitehouse.gov/the-press office/2011/01/25/remarks-president-state-unionaddress, accessed January 2014.

2. 2011 National Solar Survey, http://www.seia.org/research-resources/national-solarsurvey-2011, accessed January 2014.

3. U.S. Energy Information Administration, Electric Power Monthly Report, historical archive maintained online at: http://www.eia.gov/electricity/monthly/index.cfm, accessed January 2014.

4. U.S. Department of Energy, Fiscal Year 2013 Budget.

5. Solar Energy Industries Association, SHOTT Solar Barometer 2011.

6. Bioengineering Educational Materials Bank website, http://www.bioemb.net, accessed January 2014.

7. Materials Digital Library Pathway website, http://matdl.org, accessed January 2014.

8. Massachusetts Institute of Technology Open Courseware website, http://ocw.mit.edu, accessed January 2014.

9. Multimedia Educational Resource for Learning and Online Teaching website, http://www.merlot.org, accessed January 2014.

10. Hydrogen Education Modules, http://www.che.msstate.edu/pdfs/h2ed/, accessed January 2014.

11. Energy Modules, http://www.che.msstate.edu/pdfs/energy/index.html, accessed Janary 2014. 
Appendix: Sample Module on Basics of Solar Energy

\title{
CACHE Modules on Energy in the Curriculum The Power of Solar Energy
}

\author{
Module Title: Solar Energy Obtained in One Day \\ Module Author: Liz Rayfield and Jason Keith \\ Author Affiliation: Mississippi State University
}

References: [1]Schaeffer, John. Real Goods Solar Living Source Book: Your Complete Guide to Renewable Energy Technologies and Sustainable Living. $30^{\text {th }}$ Anniversary ed. Hopland: New Society Publishers, 2008. Print.

[2] BP Statistical Review of World Energy, June 2011, available online at: http://www.bp.com/assets/bp_internet/globalbp/globalbp_uk_english/reports_and_publications/st atistical_energy_review_2011/STAGING/local_assets/pdf/statistical_review_of_world_energy_f ull_report_2011.pdf

[3] Mississippi Energy Fact Sheet, Energy Information Administration, available online at: http://www.eia.gov/state/state-energy-profiles-print.cfm?sid=MS

Concepts: Solar power available in one day converted to power to fuel earth for 4-5 years

\section{Problem Motivation:}

In his text of the $30^{\text {th }}$ anniversary edition of the Solar Living Source Book: Your Complete Guide to Renewable Energy Technologies and Sustainable Living, author John Schaeffer states that "Every single day, enough free sunlight energy falls on Earth to supply our energy needs for four to five years at our present rate of consumption" [1]. Solar cells are not a marvel of the future anymore, but research is being conducted to make them a viable and practical way to collect solar power so that our dependence on the fossil fuels may be a thing of the past.

\section{Problem Information}

\section{Problem Statement:}

At the current consumption rate of 132,000 TW-h of energy consumed a year, how many years of energy are being supplied by the sun a day?

Data: World consumption of energy: $\quad$ 132,000 TW-hr per year [2]

Hours of "full sun": $\quad 6.1$ hours a day

Solar constant: $\quad 1 \mathrm{~kW} / \mathrm{m}^{2}$

Land Area of Earth: $\quad 1.49 * 10^{14} \mathrm{~m}^{2}$ 


\section{Solution:}

We begin by multiplying the hours of full sun, which is the maximum number of hours per day of direct sunshine with the incoming power flux of one kilowatt per square meter to get the insolation. This is not exact because we did not take into account the efficiency rate of PV panels or the fact that the entire earth is not going to get exactly 6.1 hours of full sun everywhere. Thus, hours multiply with $\mathrm{kW} / \mathrm{m}^{2}$ to produce $\mathrm{kW}-\mathrm{hr} / \mathrm{m}^{2}$, such that:

\section{$6.1 \mathrm{hr}\left(1 \mathrm{~kW} / \mathrm{m}^{2}\right)=6.1 \mathrm{~kW}-\mathrm{hr} / \mathrm{m}^{2}$}

We can then multiply this number by the amount of land area on the earth to get the amount of solar energy reaching the earth. We note that we multiply by land area and not the total surface area of the earth because we do not want to take into account how much energy would be harvested above earth's lakes and oceans, but rather those that could be harvested by land-based panels. When multiplying $\mathrm{kW}-\mathrm{hr} / \mathrm{m}^{2}$ times $\mathrm{m}^{2}$, the square meters cancel leaving $\mathrm{kW}$-hr.

$\left(6.1 \mathrm{~kW}-\mathrm{hr} / \mathrm{m}^{2}\right) *\left(1.49 * 10^{14} \mathrm{~m}^{2}\right)=9.089 * 10^{14} \mathrm{~kW}-\mathrm{hr}$

We then convert $\mathrm{kW}$-h to TW-h, using the fact that there are $10^{9} \mathrm{~kW}$-hr in one TW-hr.

$\left(9.089 * 10^{14} \mathrm{~kW}-\mathrm{hr}\right) *\left(1 \mathrm{TW}-\mathrm{h} / 1 * 10^{9} \mathrm{~kW}-\mathrm{hr}\right)=908,900 \mathrm{TW}-\mathrm{hr}$ a day

Finally, we can use the energy found in a day in TW-hr divided by the energy per year to find how many years of Earth's energy demands that one day of solar energy will power.

908,900TW-hr per day / 132,000 TW-hr per year = 6.9 years of energy

This is close to the number reported by Schaeffer.

\section{Home Problem:}

In this problem we will investigate the potential for solar energy over the land area of the state of Mississippi.

Part 1.) How much of world energy usage can come from the state of Mississippi?

Part 2.) How long could one day of full sun power the state of Mississippi at the current energy consumption rate?

Part 3.) How many acres of land would be needed to power the state of Mississippi?

Data: Land area of MS: $\quad$ 46,977 square miles

Full sun hours: $\quad 4.5$ hours

Solar constant: $\quad 1 \mathrm{~kW} / \mathrm{m}^{2}$ 
World consumption of energy:

Total consumption of energy in MS:
132,000 TW-hr per year

1,138.7 Trillion Btu [3]

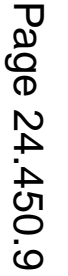


Appendix: Sample Module on Solar Energy Panel Output

\section{CACHE Modules on Energy in the Curriculum Energy Topic: Solar Energy}

Module Title: Fill Factor for Solar Cells

Module Author: Niraj Palsule and Jason Keith

Author Affiliation: Mississippi State University

Reference: Abhik Kumar, Das. "An Explicit J-V Model Of A Solar Cell For Simple Fill Factor Calculation." Solar Energy 85. (2011): 1906-1909. ScienceDirect. Web. 28 Nov. 2012.

Concepts: Maximum current-density, maximum voltage and fill factor of solar cells.

\section{Background Information:}

We define $V_{\text {oc }}$ as the open circuit voltage i.e. $V$ when $J=0$ and $J_{s c}$ as the short circuit current density i.e. $\mathrm{J}$ when $\mathrm{V}=0$.

\section{Example Problem Statement:}

It is customary to use the normalized voltage $\mathrm{v}$ and the normalized current density $\mathrm{j}$ such that $\mathrm{v}=$ $\mathrm{V} / \mathrm{V}_{\text {oc }}$ and $\mathrm{j}=\mathrm{J} / \mathrm{J}_{\mathrm{sc}}$.

Derive the following equation for Fill Factor of a solar cell: $F F=\left(\frac{m}{n}\right)^{\frac{1}{n}}\left(1+\frac{m}{n}\right)^{-\left(\frac{1}{m}+\frac{1}{n}\right)}$

provided that $(v)^{m}+(j)^{n}=1$ which was shown to be a reasonable approximation by Das. The Fill Factor of a solar cell is the ratio of maximum power of the solar cell to the product of open circuit voltage and short circuit current.

Hence we can obtain the following plot of $(v)^{\mathrm{m}}+(\mathrm{j})^{\mathrm{n}}=1$ where $\mathrm{m}$ and $\mathrm{n}$ are variables: 


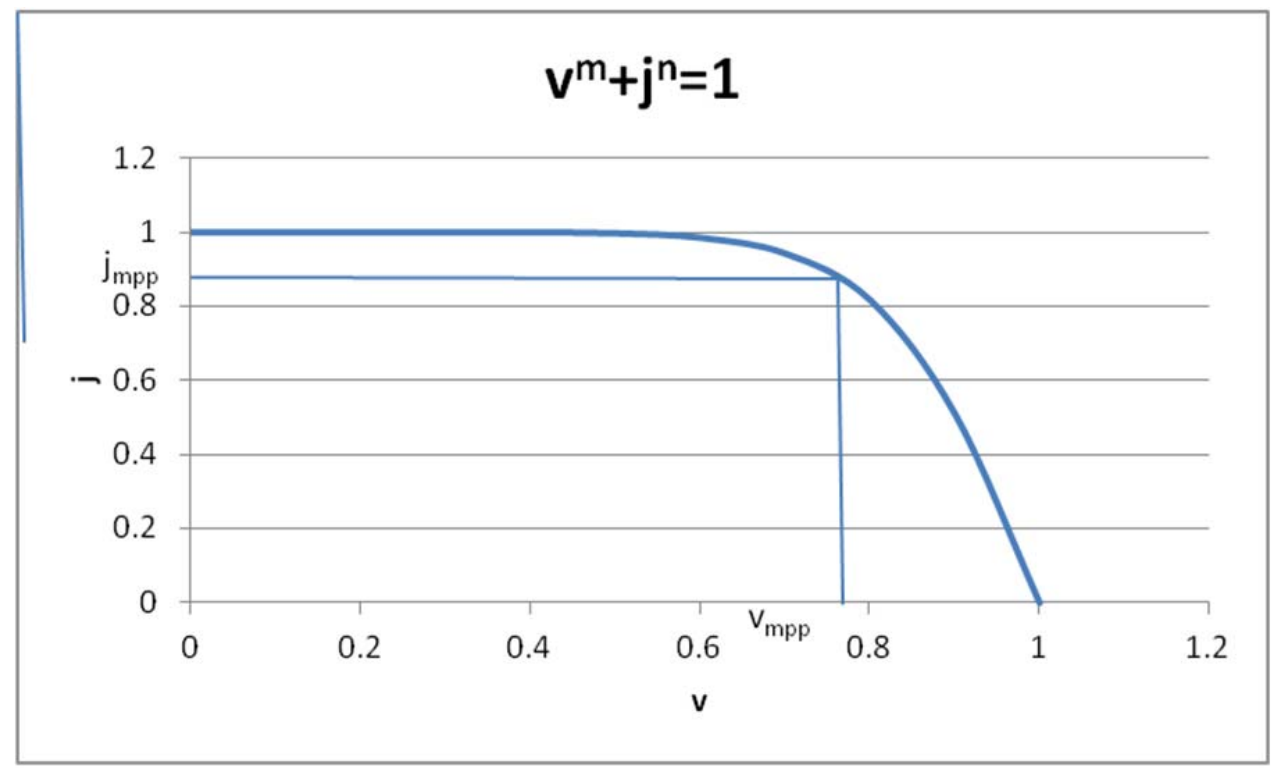

Figure 1. Reduced current $\mathrm{j}$ as a function of reduced voltage v.

Also, in order to find maximum normalized voltage, we need a plot of jv vs v.

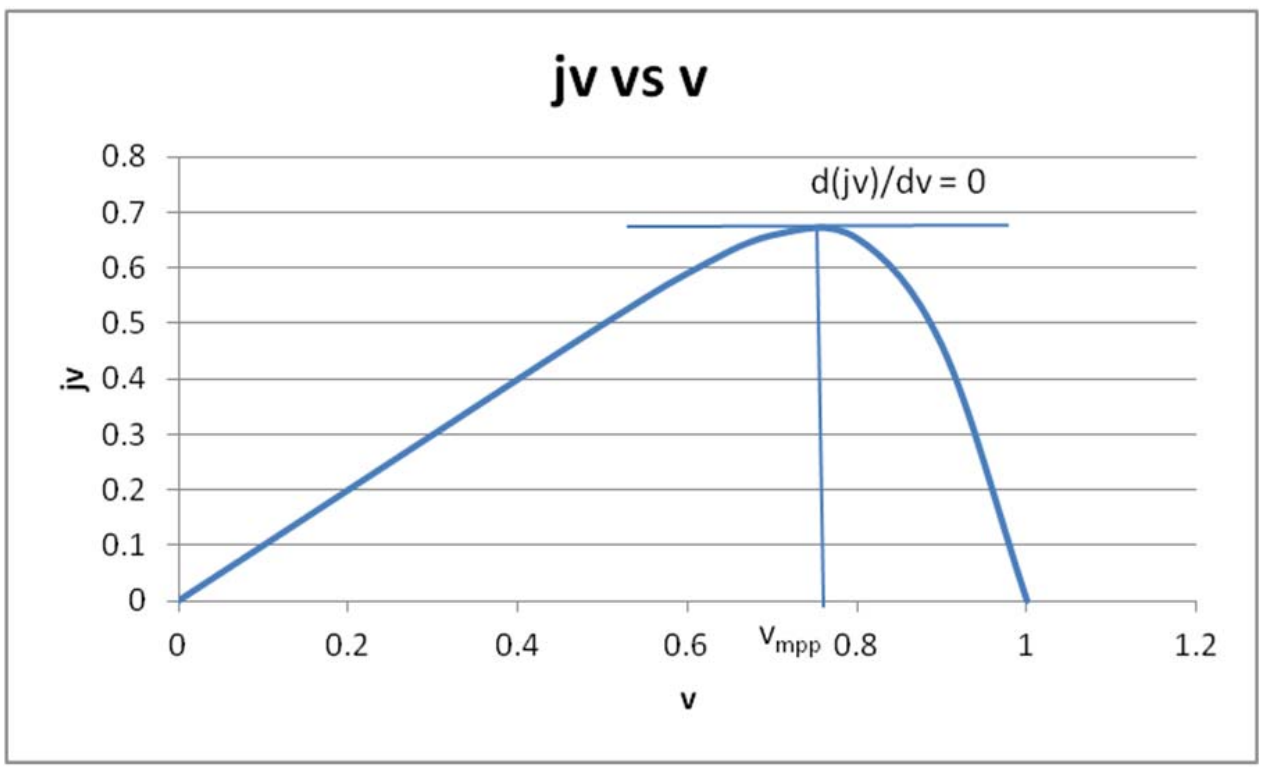

Figure 2. Reduced power jv as a function of reduced voltage v.

By inspection of figure 2 , we can see an optimum power at $\mathrm{v}_{\mathrm{mpp}}=0.76$. Then, referring to figure 1 , when $\mathrm{v}=\mathrm{v}_{\mathrm{mpp}}$ we have $\mathrm{j}=\mathrm{j}_{\mathrm{mpp}}=0.88$. Thus, $\mathrm{FF}=\mathrm{v}_{\mathrm{mpp}} \mathrm{j}_{\mathrm{mpp}}=0.67$. Ideally the fill factor for a solar material is as close to unity as possible. This would occur with a much sharper bend in the graph of figure 1 . 


\section{Example Problem Solution:}

Given $(v)^{\mathrm{m}}+(\mathrm{j})^{\mathrm{n}}=1$ and solving for $j$, we have:

$j=\left(1-v^{m}\right)^{\frac{1}{n}}$

Therefore, the normalized power $(j v)$ is given as:

$$
j v=v \times\left(1-v^{m}\right)^{\frac{1}{n}}
$$

Using the chain rule we can show that,

$$
\begin{aligned}
\frac{\mathrm{d}(\mathrm{jv})}{\mathrm{dv}} & =\left[v \times \frac{1}{n} \times\left(1-v^{m}\right)^{\frac{1}{n}-1}\right] \times\left[(-1)\left(m v^{m-1}\right)\right]+\left(1-v^{m}\right)^{\frac{1}{n}} \\
& =\left[-\frac{m v^{m}}{n\left(1-v^{m}\right)}+1\right]\left(1-v^{m}\right)^{\frac{1}{n}}
\end{aligned}
$$

which was obtained upon rearrangement. Therefore, $\frac{d(j v)}{d v}=0$ when,

$\left.\left[-\frac{m v^{m}}{n\left(1-v^{m}\right)}+1\right]\right]\left(1-v^{m}\right)^{\frac{1}{n}}=0$

This occurs when the sum in brackets is zero. That is,

$$
\left[\frac{m v^{m}}{n\left(1-v^{m}\right)}\right]=1
$$

Cross multiplying,

$$
m v^{m}=n\left(1-v^{m}\right)
$$

Rearranging, $(m+n) v^{m}=n$

Thus, $v^{m}=\frac{n}{(n+m)}$

Finally, $v=\left(\frac{n}{n+m}\right)^{\frac{1}{m}}$ 
Alternatively, $v=\left(\frac{n+m}{n}\right)^{\frac{-1}{m}}$

Finally, we obtain: $v_{m p p}=\left(1+\frac{m}{n}\right)^{\frac{-1}{m}}$

Now if we substitute this value in $j=\left(1-v^{m}\right)^{\frac{1}{n}}$ we get,

$\mathrm{j}_{\mathrm{mpp}}=\left[1-\left(1+\frac{m}{n}\right)^{-1}\right]^{\frac{1}{n}}$

Which can be written as:

$$
\mathrm{j}_{\mathrm{mpp}}=\left[1-\frac{1}{\left(1+\frac{m}{n}\right)}\right]^{\frac{1}{n}}
$$

Expanding, we obtain:

$\mathrm{j}_{\mathrm{mpp}}=\left[\frac{1+\frac{m}{n}-1}{\left(1+\frac{m}{n}\right)}\right]^{\frac{1}{n}}$

which can also be written as:

$\mathrm{j}_{\mathrm{mpp}}=\left(\frac{m}{n}\right)^{\frac{1}{n}}\left(1+\frac{m}{n}\right)^{\frac{-1}{n}}$

For the Fill Factor, $F F=\left(v_{\mathrm{mpp}}\right)\left(\mathrm{j}_{\mathrm{mpp}}\right)$

$$
\mathrm{FF}=\left(1+\frac{m}{n}\right)^{\frac{-1}{m}}\left(\frac{m}{n}\right)^{\frac{1}{n}}\left(1+\frac{m}{n}\right)^{\frac{-1}{n}}
$$

Which can be written as: 
$\mathrm{FF}=\left(\frac{m}{n}\right)^{\frac{1}{n}}\left(1+\frac{m}{n}\right)^{-\left(\frac{1}{m}+\frac{1}{n}\right)}$

\section{Home Problem Statement:}

1. Show that $m=\frac{\log \left[\frac{\log \left(j_{a}\right)}{\log \left(j_{b}\right)}\right]}{\log \left(\frac{a}{b}\right)}$ and $n=\frac{-a^{m}}{\log \left(j_{a}\right)}$ given that

$n \log (\mathrm{j})=\log \left(1-\mathrm{v}^{\mathrm{m}}\right)$ and at $\mathrm{v}=\mathrm{a}, \mathrm{j}=\mathrm{j}_{\mathrm{a}}$ and $\mathrm{at} \mathrm{v}=\mathrm{b}, \mathrm{j}=\mathrm{j}_{\mathrm{b}}$. In your derivations, assume that the value $\mathrm{v}^{\mathrm{m}}<<1$ such that $\log \left(1-\mathrm{v}^{\mathrm{m}}\right) \sim-\mathrm{v}^{\mathrm{m}}$.. (since $\mathrm{v}^{\mathrm{m}}<<1$ ).

2. For a silicon solar cell with $m=12.7$ and $n=1.14$, find the fill factor.

3. Find $\mathrm{m}$ and $\mathrm{n}$ when current density at $0.441 \mathrm{~V}$ is $63.0 \mathrm{mAcm}^{-2}$ and at $0.405 \mathrm{~V}$ is $54.9 \mathrm{mAcm}^{-2}$. Assume the open circuit voltage and short circuit current density to be constant at $0.9 \mathrm{~V}$ and 1.5 $\mathrm{mAcm}{ }^{-2}$. 